\title{
Clinical Trials in Elderly Ovarian Cancer Patients - Does It Make Sense?
}

\author{
Walther Kuhn \\ Department of Obstetrics and Gynecology, Center for Integrated Oncology Köln Bonn (ClO), University Hospital Bonn, Germany
}

The standard of care for ovarian cancer patients, mostly diagnosed in advanced tumor stages due to insufficient screening tests, is the combination of attempted complete tumor resection by cytoreductive surgery and platinum-taxane based combination chemotherapy. This generally accepted strategy has been established as the result of large national and international randomized multicenter clinical trials. Surgical cytoreduction, chemotherapeutical agents, application route, and scheduling are clearly defined today [1-5]. In contrast to oncologic surgery of other abdominal solid tumors, radical surgery even in advanced tumor stages with peritoneal carcinomatosis is a generally accepted strategy for patients with ovarian cancer, because of the distinct chemosensitivity of ovarian cancer. Over the last decades the prognosis of ovarian cancer patients has significantly improved by applying this multimodal treatment, even though the cure rate in advanced stages is not yet acceptable [6]. However, this improvement of prognosis does not apply to all patient subgroups: In 1994 the 'Hightower' report presented the data of the American College of Surgeons Cancer Commission in ovarian cancer where an age dependent worsening of the prognosis was demonstrated in elderly patients. Rates of complete tumor resection and completion of combination chemotherapy were significantly lower in the elderly patient population explaining at least partially the worse outcome [7].

In the current issue of ONKOLOGIE Hilpert and co-workers clearly specify this 'dilemma': After retrospective analysis of 3 AGO (German Gynecologic Oncology Group) clinical trials evaluating different chemotherapy regimens they present the following findings: Elderly patients are underrepresented in clinical trials, chemotherapy application and tumor resection are more often incomplete, and survival time is significantly shorter compared to younger patients. These results are striking and should lead to changes in treatment decisions and oncologic management in the elderly population. So far, however, there is no clear and clinically applicable definition which patient should be categorized as 'elderly' and who as 'younger' patient. Organ function, behavioral state, and cognitive skills have to be adequate to undergo demanding surgical and chemotherapeutical treatment. It is the physician's responsibility to perform a correct assessment and to select the appropriate elderly patients for oncologic treatment within clinical trials. By using different geriatric assessment tools, e.g. presented by Balducci and co-workers, a clinically manageable assessment is feasible [8]. It has to be noted that in the so-called elderly patient, organ function (especially cardiac, renal and pulmonary) can be compromised and that there is a higher susceptibility in the elderly for chemotherapy induced myelosuppression as well as for neuro- and nephrotoxicity [9]. These potential impairments, however, do not depend on the chronological but the biological age. Thus, a 85-year-old, biologically 'young' patient could be assessed as an appropriate candidate for debulking surgery and polychemotherapy within a clinical trial, whereas a 60-year-old patient with limited cognitive skills and comorbidities will not be recruited to a clinical trial and will undergo individualized oncologic treatment. In routine clinical care, an experienced physician realizes this complexity and a careful and responsible decision-making is necessary.

Hilpert and co-workers underline that more elderly patients should be recruited in clinical trials. This seems to be feasible because the characteristics of patients included in and excluded from the analyzed clinical trials were similar, suggesting that the non-enrolled patients can potentially tolerate the study treatment. Recruitment of elderly patients for clinical trials should be attempted, however, because of the retrospective character of the analysis with post-hoc subgroup formation a substantial selection bias is implied. Thus, elderly patients who are not candidates for conventional clinical trials should be treated in clinical trials especially designed for the elderly population. There are data demonstrating that the elderly could benefit from neoadjuvant chemotherapy followed by debulking surgery and postoperative chemotherapy, because behavioral state and tumor resectability are hereby improved [10,11].

\section{KARGER \\ Fax +497614520714 \\ Information@Karger.de}

www.karger.com (c) 2012 S. Karger GmbH, Freiburg

0378-584X/12/0353-0073\$38.00/0

Accessible online at:

www.karger.com/onk
Prof. Dr. med. Walther Kuhn

Medizinische Einrichtungen der

Rheinischen Friedrich-Wilhelms-Universität

Sigmund-Freud-Str. 25, 53105 Bonn, Germany

Tel. +49 228 287-15444, Fax -6091

walther.kuhn@ukb.uni-bonn.de 
Patient care and perhaps prognosis are better if treatment and follow-up are delivered within a clinical trial according to a pre-defined study-protocol. The authors' commitment to intensify the recruitment of the elderly in clinical trials has to be supported, taking into account that the necessity to perform a correct geriatric assessment will be the key issue not only for the recruitment in conventional intravenous chemotherapy trials. Numerous 'biologicals' including antibody treatment as well as other routes of chemotherapy application, such as intraperitoneal with or without hyperthermic treatment ('HIPEC') will be analyzed within clinical trials in the near future [12-15]. A high level of expertise is warranted for patient assessment; therefore it is to be discussed whether elderly ovarian cancer patients should be exclusively treated in highly specialized ovarian cancer centers. The positive impact on the outcome of patients irrespective of age by delivering oncologic treatment in experienced cancer units has already been proven [16]. Finally it has to be reflected that age is an independent prognostic parameter for overall survival. Thus, the prognosis of the elderly is genuinely worse compared to similarly treated younger patients. The reason for this tumor biologically driven prognosis may be in part attributable to chemoresistance $[17,18]$.

There are ongoing secondary ovarian cancer prevention trials especially in the United Kingdom using screening vaginal sonography in combination with different serologic tumor markers. So far the results of these trials, similarly under-representing the elderly population, have been disappointing [19, 20]. Enrollment of the elderly may have a positive impact on the screening results due to the age dependent higher disease prevalence.

Clinical research needs clinical trials, new and generally applicable knowledge can only be acquired if the young and the old participate in clinical trials.

\section{Disclosure Statement}

There is nothing to disclose.

\section{References}

1 Hoskins WJ, Bundy BN, Thigpen JT, Omura GA: The influence of cytoreductive surgery on recurrence-free interval and survival in small-volume stage III epithelial ovarian cancer: a Gynecologic Oncology Group study. Gynecol Oncol 1992; 47:159-166.

2 du Bois A, Lück HJ, Meier W, Adams HP Möbus V, Costa S, Bauknecht T, Richter B, Warm M, Schröder W, Olbricht S, Nitz U, Jackisch C, Emons G, Wagner U, Kuhn W, Pfisterer J; Arbeitsgemeinschaft Gynäkologische Onkologie Ovarian Cancer Study Group: A randomized clinical trial of cisplatin/paclitaxel versus carboplatin/paclitaxel as first-line treatment of ovarian cancer. J Natl Cancer Inst 2003;95:1320 1329.

3 McGuire WP, Hoskins WJ, Brady MF, Kucera PR, Partridge EE, Look KY, Clarke-Pearson DL, Davidson M: Cyclophosphamide and cisplatin compared with paclitaxel and cisplatin in patients with stage III and stage IV ovarian cancer. N Engl J Med 1996;334:1-6.

4 Chi DS, Eisenhauer EL, Zivanovic O, Sonoda Y, Abu-Rustum NR, Levine DA, Guile MW, Bristow RE, Aghajanian C, Barakat RR: Improved progression-free and overall survival in advanced ovarian cancer as a result of a change in surgical paradigm. Gynecol Oncol 2009;114:26-31.

$\checkmark 5$ Bristow RE, Tomacruz RS, Armstrong DK, Trimble EL, Montz FJ: Survival effect of maximal cytoreductive surgery for advanced ovarian carcinoma during the platinum era: a meta-analysis. J Clin Oncol 2002;20:1248-1259.

6 6 Heintz AP, Odicino F, Maisonneuve P, Quinn MA, Benedet JL, Creasman WT, Ngan HY, Pecorelli S, Beller U: Carcinoma of the ovary. FIGO 26th Annual Report on the Results of Treatment in Gynecological Cancer. Int J Gynaecol Obstet 2006; 1:161-192.
7 Hightower RD, Nguyen HN, Averette HE, Hoskins W, Harrison T, Steren A: National survey of ovarian carcinoma. IV: Patterns of care and related survival for older patients. Cancer 1994; 73:377-383.

8 Balducci L, Colloca G, Cesari M, Gambassi G: Assessment and treatment of elderly patients with cancer. Surg Oncol 2010;19:117-123.

9 Balducci L: Pharmacology of antineoplastic medications in older cancer patients. Oncology [Williston Park] 2009;23:78-85.

10 Vergote I, Tropé CG, Amant F, Ehlen T, Reed NS, Casado A: Neoadjuvant chemotherapy is the better treatment option in some patients with stage IIIc to IV ovarian cancer. J Clin Oncol 2011;29: 4076-4078.

11 Pölcher M, Braun M, Friedrichs N, Rudlowski C, Bercht E, Fimmers R, Sauerwald A, KeyverPaik MD, Kübler K, Büttner R, Kuhn WC, Hernando JJ: Foxp3 [+] cell infiltration and granzyme $\mathrm{B}[+] /$ Foxp $3[+]$ cell ratio are associated with outcome in neoadjuvant chemotherapy-treated ovarian carcinoma. Cancer Immunol Immunother 2010;59:909-919.

12 Burger RA, Brady MF, Bookman MA, Fleming GF, Monk BJ, Huang H, Mannel RS, Homesley HD, Fowler J, Greer BE, Boente M, Birrer MJ, Liang SX; Gynecologic Oncology Group: Incorporation of bevacizumab in the primary treatment of ovarian cancer. N Engl J Med 2011;365:2473-2483.

13 Perren TJ, Swart AM, Pfisterer J, Ledermann JA, Pujade-Lauraine E, Kristensen G, Carey MS, Beale P, Cervantes A, Kurzeder C, du Bois A, Sehouli J, Kimmig R, Stähle A, Collinson F, Essapen S, Gourley C, Lortholary A, Selle F, Mirza MR, Leminen A, Plante M, Stark D, Qian W, Parmar MK, Oza AM; ICON7 Investigators: A phase 3 trial of bevacizumab in ovarian cancer. N Engl J Med 2011;365:2484-2496.
14 Armstrong DK, Bundy B, Wenzel L, Huang HQ, Baergen R, Lele S, Copeland LJ, Walker JL, Burger RA; Gynecologic Oncology Group: Intraperitoneal cisplatin and paclitaxel in ovarian cancer. N Engl J Med 2006;354:34-43.

15 Deraco M, Kusamura S, Virzì S, Puccio F, Macrì A, Famulari C, Solazzo M, Bonomi S, Iusco DR, Baratti D: Cytoreductive surgery and hyperthermic intraperitoneal chemotherapy as upfront therapy for advanced epithelial ovarian cancer: multi-institutional phase-II trial. Gynecol Oncol 2011;122: 215-220.

16 Bristow RE, Zahurak ML, Diaz-Montes TP, Giuntoli RL, Armstrong DK: Impact of surgeon and hospital ovarian cancer surgical case volume on in-hospital mortality and related short-term outcomes. Gynecol Oncol 2009;115:334-338.

17 Tew WP, Lichtman SM: Ovarian cancer in older women. Semin Oncol 2008;35:582-589.

18 Chan JK, Tian C, Monk BJ, Herzog T, Kapp DS, Bell J, Young RC; Gynecologic Oncology Group: Prognostic factors for high-risk early-stage epithelial ovarian cancer: a Gynecologic Oncology Group study. Cancer 2008;112:2202-2210.

19 Nobbenhuis MA, Bancroft E, Moskovic E, Lennard F, Pharoah P, Jacobs I, Ward A, Barton DP, Ind TE, Shepherd JH, Bridges JE, Gore M, Haracopos C, Shanley S, Ardern-Jones A, Thomas $\mathrm{S}$, Eeles R: Screening for ovarian cancer in women with varying levels of risk, using annual tests, results in high recall for repeat screening tests. Hered Cancer Clin Pract 2011;9:11.

20 Sharma A, Gentry-Maharaj A, Burnell M, Fourkala EO, Campbell S, Amso N, Seif M, Ryan A, Parmar M, Jacobs I, Menon U; for the UK Collaborative Trial of Ovarian Cancer Screening (UKCTOCS): Assessing the malignant potential of ovarian inclusion cysts in postmenopausal women within the UK Collaborative Trial of Ovarian Cancer Screening (UKCTOCS): a prospective cohort study. BJOG 2012;119:207-219. 